\title{
A CROSS SECTIONAL STUDY ON STILLBIRTHS AT A TERTIARY CARE CENTRE AND TEACHING HOSPITAL
}

\author{
Patil Hema $S^{1}$, Faliya Dipti², Parveen Haseena 3 , Jahanvi $A^{4}$
}

${ }^{1}$ Associate Professor, Department of Obstetrics and Gynaecology, KLE University's JNMC, Belagavi, Karnataka. 2 Postgraduate Student, Department of Obstetrics and Gynaecology, KLE University's JNMC, Belagavi, Karnataka. ${ }^{3}$ Postgraduate Student, Department of Obstetrics and Gynaecology, KLE University's JNMC, Belagavi, Karnataka. ${ }^{4}$ Postgraduate Student, Department of Obstetrics and Gynaecology, KLE University's JNMC, Belagavi, Karnataka.

\begin{abstract}
BACKGROUND

The World Health Organization defines perinatal mortality as the "number of stillbirths and deaths in the first week of life per 1,000 total births, the perinatal period commences at 22 completed weeks (154 days) of gestation and ends seven completed days after birth. ${ }^{1}$ The level of perinatal mortality is associated with socioeconomic development and availability of health care facilities in the community.2,3,4 Perinatal mortality is also an indicator of social equity and health care standard of a community. Perinatal includes early neonatal mortality. Neonatal mortality is becoming increasingly important not only because the proportion of under-five deaths that occur during the neonatal period is increasing although under-five mortality is declining but also because the health interventions needed to address the major causes of neonatal deaths generally differ from those needed to address other under-five deaths and are intimately linked to those that are necessary to protect maternal health. The first day and week are most critical for the survival of newborns. Children that die in the first 28 days of life suffer from diseases and conditions that are often associated with quality of care around the time of childbirth and are readily preventable or treatable. ${ }^{3}$ Analysing the determinants of perinatal mortality can help in finding the causes and planning effective and corrective measures to improve the perinatal outcomes. Also this can be extrapolated to huge health benefits in terms of improvement of neonatal, infant and und erfive survival rates. Hence, this study was done to find out the incidence and evaluate the causes associated with stillbirths.
\end{abstract}

\section{MATERIALS AND METHODS}

Study Design- A retrospective cross-sectional study.

Source of Data- Medical records from Department of Obstetrics and Gynaecology, attached to KLE University's J. N. Medical College. Sample- 220 cases for a period of one year from January 2014-December 2014 were analysed.

Data Analysis- Demographic variables were analysed by pie charts and bar diagrams.

\section{RESULTS}

There were 6270 deliveries during January 2014 to December 2014. There were 220 stillbirths which occurred during this period that were analysed, amounting to an incidence of 35 per 1000 live births. Fresh stillbirths accounted for $62 \%$ of stillbirths. The mean maternal age of stillbirths is $26.7 \pm 4.2$ years. $42 \%$ of the stillbirths occurred in unregistered cases. Low socioeconomic status contributed to $38 \%$ of stillbirths. Majority of these stillbirths occurred in primigravida (40\%). Maternal causes were hypertensive disorders of pregnancy (22.4\%), antepartum haemorrhage (14\%), preterm labour (13.7), gestational diabetes mellitus (5.5\%). The mean gestational age at time of delivery was 32 weeks, with mean birth weight of $1.46 \mathrm{Kg} .72$ (32\%) out of 220 stillbirths occurred before 28 weeks, 46 (20.9\%) occurred between 28 - 32 weeks, 39 (17.7\%) cases from 32 - 34 weeks, 38 (17.2\%) cases from 34 37 weeks, 25 (11.3\%) cases from $37-42$ weeks. The major foetal cause of the stillbirth was prematurity (14\%).

\section{CONCLUSION}

Stillbirth rate in our institute was correlating with the national perinatal mortality rate (35 vs. 22-60). Majority of the stillbirths occurred in unregistered cases suggesting that they can be prevented with effective antenatal care and close monitoring especially for growth restricted foetuses.

\section{KEYWORDS}

Perinatal Mortality, Neonatal Mortality, Intrauterine Deaths, Fresh Stillbirths, Macerated Stillbirths, Foetal Growth Restriction, Hypertensive Disorders of Pregnancy, MDG.

HOW TO CITE THIS ARTICLE: Hema PS, Dipti F, Haseena P, et al. A cross sectional study on stillbirths at a tertiary care centre and teaching hospital. J. Evolution Med. Dent. Sci. 2017;6(23):1934-1938, DOI: 10.14260/Jemds/2017/424

Financial or Other, Competing Interest: None.

Submission 05-01-2017, Peer Review 03-03-2017,

Acceptance 11-03-2017, Published 20-03-2017.

Corresponding Author:

Dr. Faliya Dipti,

Postgraduate Student,

Department of Obstetrics and Gynaecology,

KLE University's JNMC, Belagavi-590010, Karnataka.

E-mail:dr.diptishah27@gmail.com

DOI: $10.14260 /$ jemds $/ 2017 / 424$

(c) $(i) \$$

\section{BACKGROUND}

Stillbirth is defined as a baby born with no signs of life at or after 20 weeks of gestation or of weight less than $500 \mathrm{~g}$. The rate of stillbirths is higher in developing countries than developed countries. ${ }^{1}$ India contributes to one fourth of the total stillbirths worldwide. ${ }^{5}$ According to recent NFHS data, stillbirth rate in India is $22-26$ per 1000 live births. ${ }^{6}$ Millennium Development Goal 4 was directed towards prevention of child mortality rates (Target 4 . A: Reduce the 
under-five mortality rate by two-thirds, between 1990 and 2015. ${ }^{7}$ )

Sustainable development goal 3.2 aims to end preventable deaths of newborns and children under 5 years of age, with all countries aiming to reduce neonatal mortality to at least as low as 12 per 1,000 live births and under-five mortality to at least as low as 25 per 1,000 live births by $2030 .{ }^{8}$ Neonatal mortality contributes to $56 \%$ of under-five mortality of which $45 \%$ is by early neonatal deaths and $11 \%$ by late neonatal deaths. ${ }^{9}$ In 2013 almost 1 million newborns (36 percent) died on the day they were born, and another 1 million (37 percent) died within the next six days of birth. Some 0.8 million neonatal deaths (27 percent) occurred between day 7 and day 27 of life. ${ }^{3}$ Most neonatal deaths are preventable. The share of neonatal deaths among under-five deaths has increased from $37 \%$ in 1990 to $44 \%$ in $2013 .{ }^{3}$ With 2.8 million newborns dying each year, accounting for 44 percent of under-five deaths, progress has been insufficient and is now impeding improvement in child survival worldwide. ${ }^{3}$ Neonatal health will need to be addressed more effectively for progress on overall child mortality to continue rapidly.

Hence, analysing the causes of perinatal mortality which includes early and late neonatal deaths, helps in formulating preventive and effective strategies to achieve SDG goals.

Stillbirth rates reflect a woman`s pre-conceptional health and nutritional status, her access to good health care including contraception, first trimester care, screening for infectious diseases and congenital anomalies, disease identification and management and adequate care during labour which includes foetal monitoring, timely access to caesarean section. Thus, stillbirth rates indicate the accessibility and quality of health care. There are many downstream consequences of stillbirths, the most significant and long lasting being experienced by mother like depression, post-traumatic stress disorder and family disorganisation.

The causes of stillbirth differ in developing countries compared to developed countries. Most common causes of stillbirth include spontaneous preterm delivery, hypertensive disorders of pregnancy, antepartum haemorrhage, multiple pregnancy and intrapartum asphyxia. Most of them can be prevented with better understanding of the causes and improvement of obstetric care. This study aims to determine the causes of stillbirth based on the antenatal and intranatal events. Thus, this study helps in analysing the risk factors and hence modulate strategies for prevention of stillbirth for better perinatal outcome.

\section{MATERIALS AND METHODS}

\section{Source of Data}

Medical records from Department of Obstetrics and Gynaecology, attached to KLE University's J. N. Medical College.

\section{Study Design}

Retrospective cross sectional study.

\section{Sample Size}

A total of 220 cases for a period of one year from January 2014 - December 2014.

Individual consent was waived off, after taking ethical clearance.

Data was collected from medical records department of teaching hospital attached to KLE University's J. N. Medical College. Data was collected regarding maternal characteristics, labour characteristics, details regarding stillbirth. Cause of the stillbirths is ascertained based on the standard definitions of antepartum haemorrhage, foetal growth restriction, hypertensive disorders of pregnancy, preterm labour and gestational diabetes mellitus.

Data analysis was done using pie charts, bar diagrams graphically.

\section{RESULTS}

\section{Maternal Characteristics}
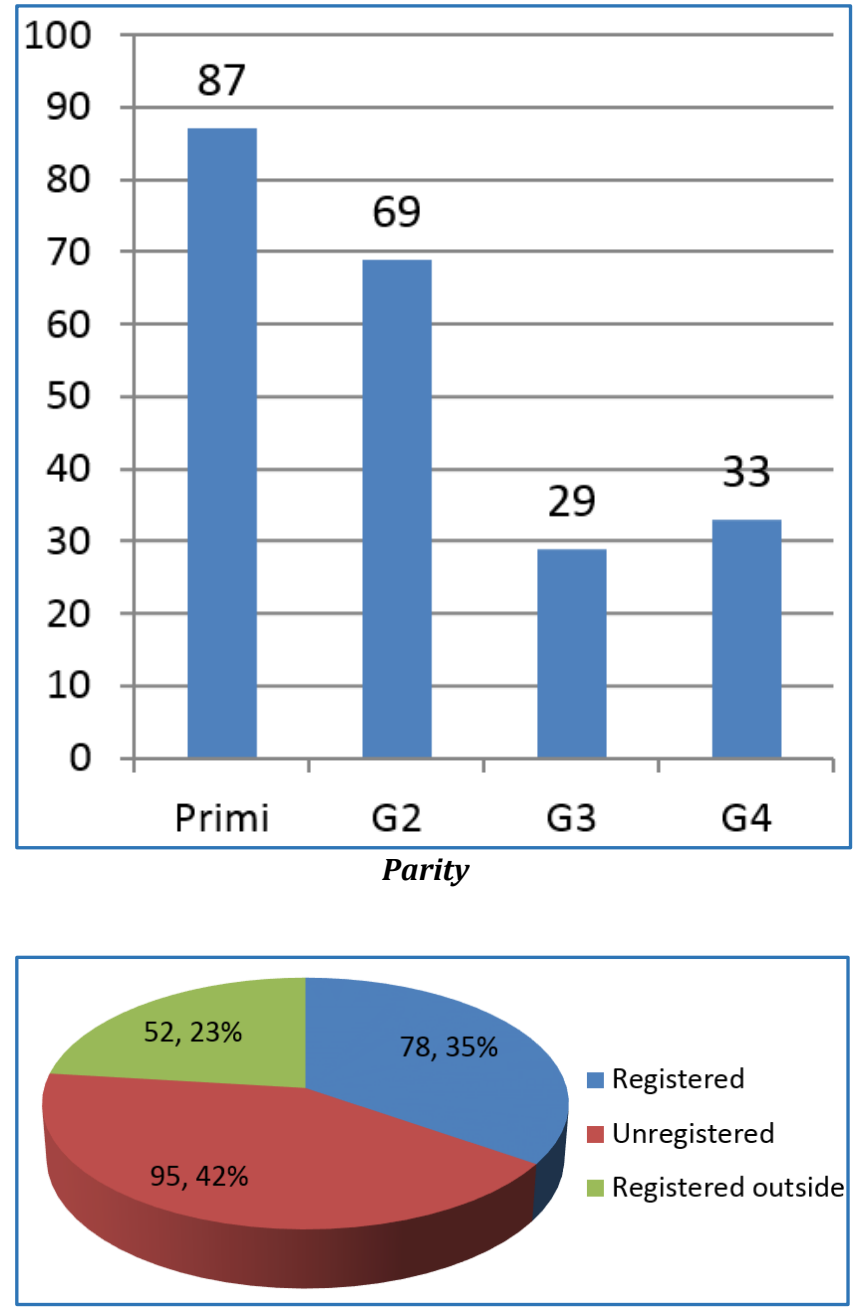

Registered vs. Unregistered 


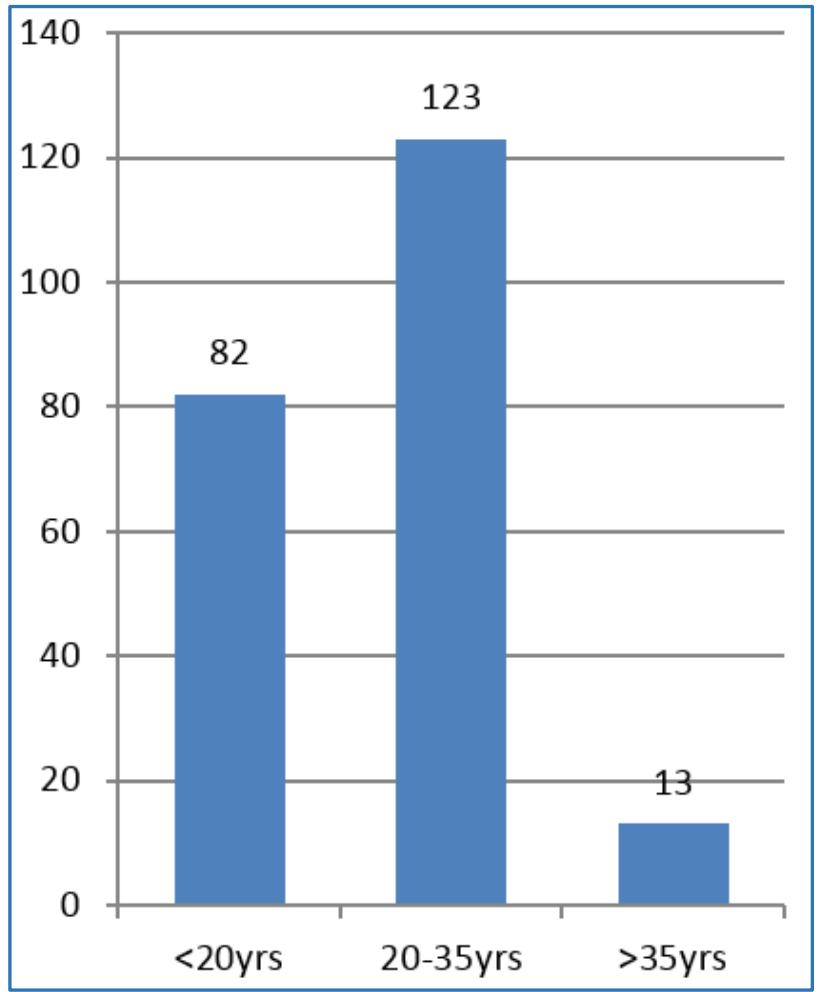

Maternal Age

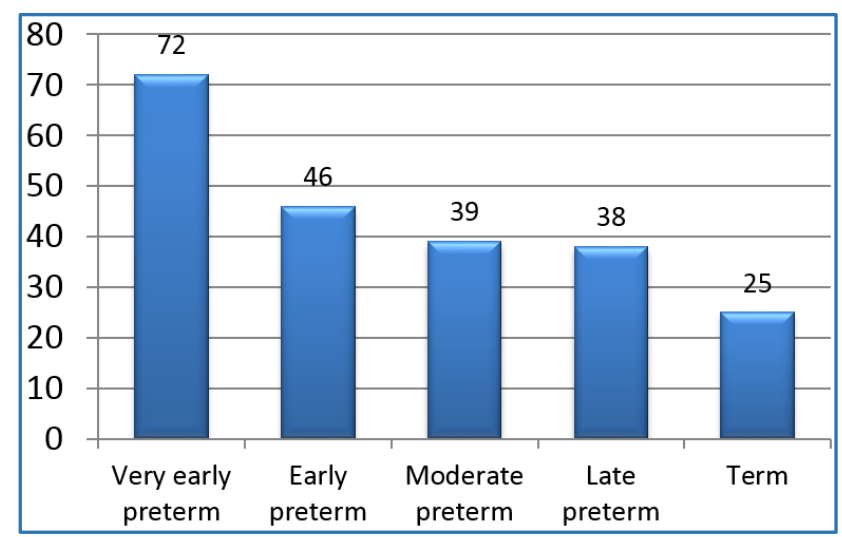

Term vs. Preterm

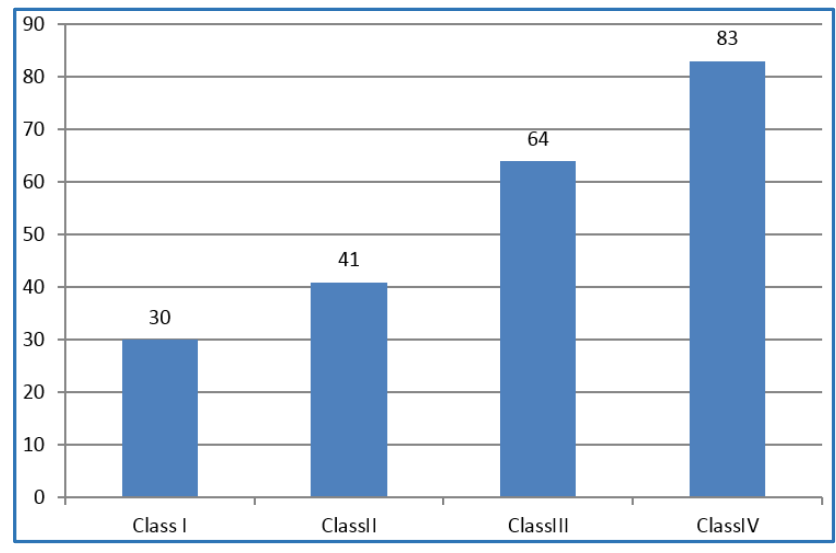

Maternal Socioeconomic status-Modified B. J. Prasad Classification

\section{Causes of Stillbirths}

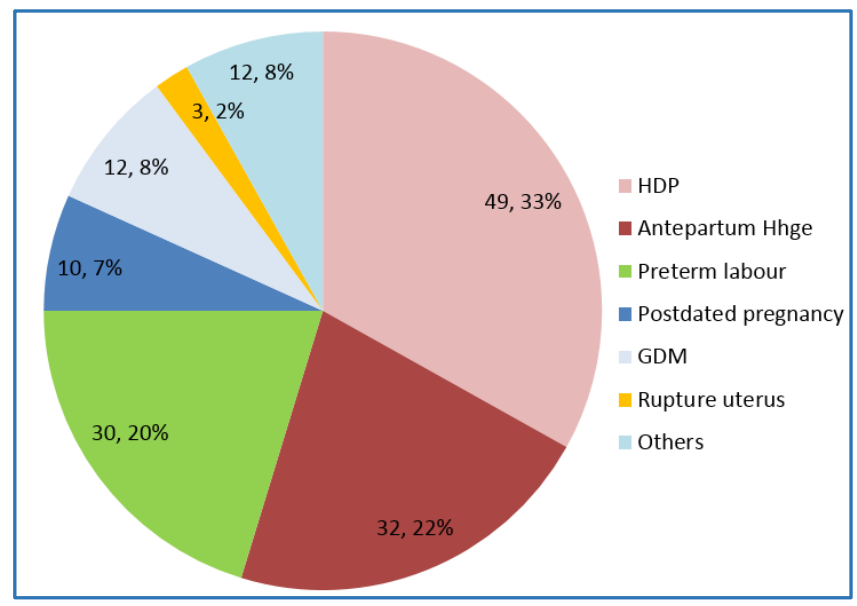

Maternal Causes

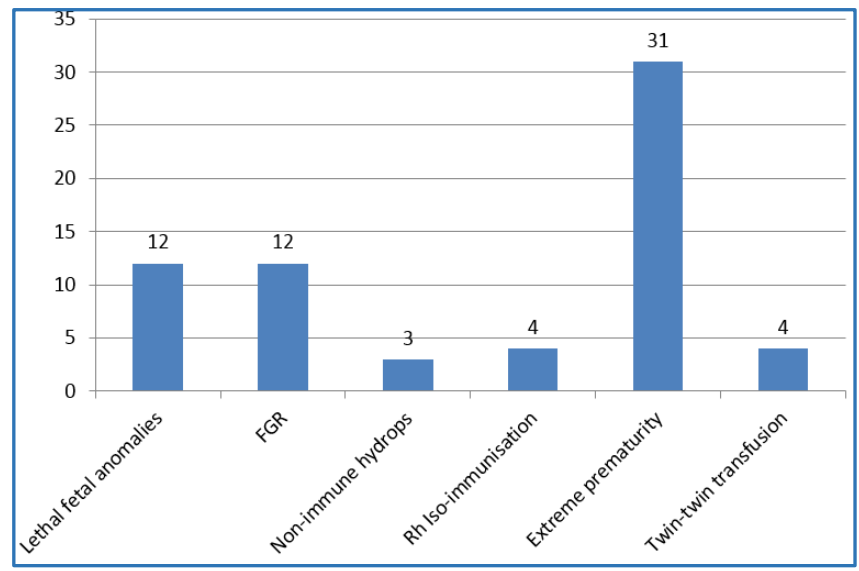

Foetal Characteristics

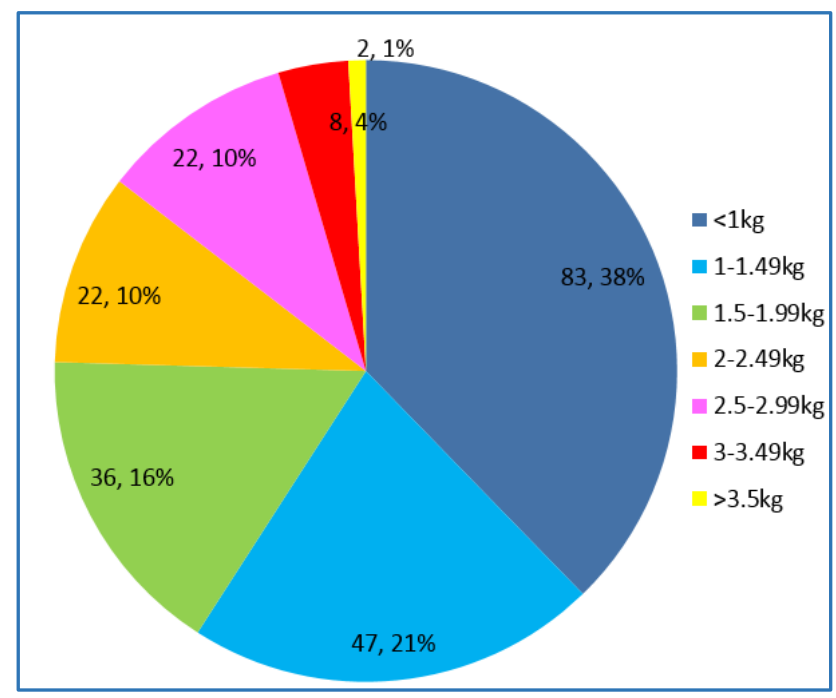

Weight of the Babies 


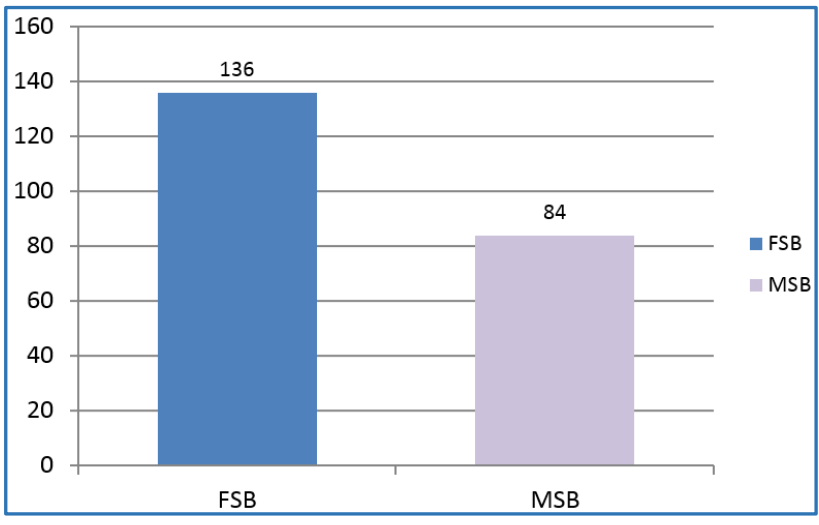

Fresh Stillbirths vs. Macerated Stillbirths

\section{RESULTS}

Stillbirth rate in this study was 35 per 1000 births. We first examined the maternal characteristics of these stillbirths. The mean maternal age of stillbirths is $26.7 \pm 4.2$ years. Majority of these stillbirths occurred in primigravida. In our study, 49 had hypertensive disorders of pregnancy, 32 had antepartum haemorrhage, 30 had preterm labour, 12 had gestational diabetes mellitus, 2 had twin gestation complicated by twinto-twin transfusion. The mean gestational age at the time of delivery was 32 weeks with mean birth weight of $1.46 \mathrm{Kg} .72$ out of 220 stillbirths occurred before 28 weeks, 46 occurred between 28 - 32 weeks, 39 cases from 32 - 34 weeks, 38 cases from 34 - 37 weeks, 25 cases from 37 - 42 weeks. $42 \%$ of the stillbirths occurred in unregistered cases. Contributing $60 \%$ to the stillbirths are maternal factors followed by foetal (30\%) and placental (10\%) factors although there exists certain degree of overlap. Most common cause of stillbirth is hypertensive disorders of pregnancy, second most common cause being antepartum haemorrhage followed by preterm labour. Foetal causes accounted for approximately 30\% of stillbirths. The most common foetal cause of stillbirth being extreme prematurity followed by foetal growth restriction. Fresh stillbirths accounted for $62 \%$ of stillbirths. The major foetal cause of the stillbirth is prematurity (14\%) as compared to other studies where it is foetal malformations $(8.3 \%)$. Majority of the stillbirths occurred in women between 20 - 35 yrs. (42\%). Low socioeconomic status appears to be a risk factor for stillbirth as they $38 \%$ of stillbirths occurred in this group in this study.

\section{DISCUSSION}

The proportion of child deaths that occur in the neonatal period (38\% in 2000) is increasing, and the Millennium Development Goal for child survival cannot be met without substantial reductions in neonatal mortality. Every year an estimated 4 million babies die in the first 4 weeks of life (the neonatal period). ${ }^{10} \mathrm{~A}$ similar number are stillborn, and 0.5 million mothers die from pregnancy-related causes. ${ }^{10}$ Threequarters of neonatal deaths happen in the first week- the highest risk of death is on the first day of life. ${ }^{10}$ Almost all (99\%) neonatal deaths are in low-income and middle-income countries, yet most epidemiological and other research focuses on the $1 \%$ of deaths in rich countries. The highest numbers of neonatal deaths are in south-central Asian countries and the highest rates are generally in sub-Saharan
Africa. ${ }^{10}$ The global rate of stillbirth is showing a declining trend. However, the rate of decline is slow in developing countries than developed countries. The majority of these stillbirths are occurring in developing countries. The stillbirth rate in our study is 35 per 1000 live births as compared to the national stillbirth rate which is ranging from 20-66 per 1000 births in different parts of India. Fresh stillbirths accounted for $62 \%$ of stillbirths as compared to the other studies where it ranges from $65-72.2 \%$. Majority of stillbirths occurred in primigravida which is correlating with other studies.11-14 Majority of stillbirths occurred in women of low socioeconomic status which is observed in other studies also.11-15 The major maternal cause of stillbirths is hypertensive disorder of pregnancy (33\%) as compared to other study done at McGill University where it contributed to $1.3 \% .^{12}$ The major foetal cause of stillbirths is extreme prematurity as opposed to developed countries where congenital anomalies contributed to majority of stillbirths. Underreporting is the major issue in developing countries as half of the stillbirths occur at home without prenatal care. 15 Therefore, there is a need to plan strategy for accurate data collection of these stillbirths. Interventions like educating and motivating pregnant women regarding the early booking visit and need for regular antenatal care, identification of high risk cases and educating them regarding the need for close surveillance and regarding the warning signs, $\mathrm{Rh}$ immunoprophylaxis, written policy for intrapartum monitoring in labour should be implemented to reduce the stillbirth rate. There should be a written policy of reporting stillbirths with database to store the data regarding the same so that it can be analysed retrospectively. Government along with local heads should be involved in educating the women regarding the need for antenatal care. Strengthening of referral system is also a need of the hour as many women end up with stillbirths because of delay in the referral.

\section{CONCLUSION}

Majority of the stillbirths can be prevented with effective antenatal and intranatal care and careful watch and expectancy policy in high risk pregnancies.

\section{REFERENCES}

[1] www.who.int/classifications/icd/ICD10Volume2_en_2 010.pdf

[2] Thomson AM, Barron SL. Perinatal mortality. In: Barron SL, Thomson AM. eds. Obstetrical epidemiology. London: Academic Press 1983:346-98.

[3] www.uniceforg/media/files/Levels_and_Trends_in_C hild_Mortality_2014.pdf

[4] Chamberlain G. Better perinatal health: background to perinatal health. Lancet 1979;314(8151):1061-3.

[5] Sankar MJ, Neogi SB, Sharma J, et al. State of newborn health in India. J Perinatol 2016;36(Suppl 3):S3-S8.

[6] rchiips.org/nfhs/NFHS-3\%20Data/VOL1/India_volume_I_corrected_17oct08.pdf

[7] Millennium development goals. http://www.un.org 2017.

[8] Sustainable development goals. http://www.un.org 2017. 
[9] Maternal, newborn, child and adolescent health. http://www.who.int 2017.

[10] Lawn JE, Cousens S, Zupan J, et al. 4 million neonatal deaths: when? Where? Why? Lancet 2005;365(9462):891-900.

[11] Were EO. Stillbirths at Eldoret district hospital: a retrospective study. East African Medical Journal 1994;71(9):607-10.

[12] Wou K, Ouellet MP, Chen MF, et al. Comparison of etiology of stillbirth over five decades in a single centre: a retrospective study. BMJ 2014;4(6):e004635.
[13] Gardosi J, Madurasinghe V, Williams M, et al. Maternal and fetal risk factors for stillbirth: population based study. British Medical Journal 2013;346:f108.

[14] Mavalankar DV, Trivedi CR, Gray RH. Levels and risk factors for perinatal mortality in Ahmedabad, India. Bull World Health Organ 1991;69(4):435-42.

[15] Zeitlin J, Combier E, De Caunes F, et al. Sociodemographic risk factors for perinatal mortality. A study of perinatal mortality in the French district of Seine-Saint-Denis. Acta Obstet Gynecol Scand 1998;77(8):826-35. 